\title{
Recensiones
}

\section{Recensión del libro La eficacia de las normas de prevención, detección y sanción del lavado de activos en Colombia}

\author{
Review of the book: The effectiveness of the rules for \\ prevention, detection, and punishment of money \\ laundering in Colombia
}

Diego Mauricio Montoya Vacadíez ${ }^{1}$

Recepción: 03/02/2021 • Aprobación: 04/02/2021 • Publicación: 30/07/2021

Para citar este artículo

Montoya Vacadíez, D. M. (2021). Recensión del libro La eficacia de las normas de prevención, detección y sanción del lavado de activos en

Colombia. Dos mil tres mil, 23, e318. https://doi.org/10.35707/dostres$\mathrm{mil} / 23318$

\section{(c) (i) () $\Theta$}

${ }^{1}$ Profesor de Derecho Penal, universidades del Rosario y La Gran Colombia. Correo electrónico: diego_9985@hotmail.com 
Resumen. En este texto se presenta una recensión del libro La eficacia de las normas de prevención, detección y sanción del lavado de activos en Colombia, destacando los contenidos de cada uno de los capítulos de esta obra colectiva.

Abstract. This text presents a review of the book "The effectiveness of the rules for prevention, detection, and punishment of money laundering in Colombia", highlighting the contents of each one of the chapters of this collective work.

\section{Palabras claves}

Lavado de activos, testaferrato, omisión de control, tipologías de lavado de activos, prevención y detección del lavado de activos, instrumentos internacionales contra el lavado de activos.

Key words

Money laundering, front man, control omission, types of money laundering, prevention and detection of money laundering, international instruments against money laundering. 


\section{Introducción}

La comunidad académica da la bienvenida a la obra La eficacia de las normas de prevención, detección y sanción del lavado de activos en Colombia, que contó con la coordinación académica del profesor Hernando Antonio Hernández Quintero (2020a), tratadista colombiano que ha producido una inmensa obra sobre el delito de blanqueo de capitales, y que tiene a este delito como eje trasversal.

Esta obra nace de la necesidad de estudiar, con profundidad, las normas relacionadas con el castigo del lavado de activos, así como de los controles que se han dispuesto para prevenir y detectar la materialización de esta conducta nociva para la vida de las naciones.

En el primer capítulo de la obra, el profesor Hernández Quintero (2020b) hace un recorrido de las normas que se han dispuesto en Colombia para la detección y sanción del lavado de activos. El autor muestra, en primera instancia, la evolución de las normas de prevención y detección de este delito, desde una etapa gremial, en la que las asociaciones de las instituciones vulnerables dictaban las normas correspondientes por las que se regirían, hasta una etapa estatal, en la que el Gobierno profiere dicha normativa, la cual va incluyendo distintos sectores, como el financiero, el real y el cooperativo.

Posteriormente, el autor entra en el campo de las normas penales dispuestas para castigar el lavado de dinero, recorrido que empieza con la Ley 190 de 1995, que tipificó el lavado de activos por primera vez en Colombia, como una forma agravada del tipo de receptación, para luego llegar a la Ley 365 de 1997, norma que le confirió a este delito su carácter autónomo y de delito contra el orden económico y social (además de crear el tipo de omisión de control), y finalmente llegar a la tipificación que se realizó en el Código Penal de 2000 (que conservó gran parte de lo realizado por la Ley 365), la cual ha sido objeto de numerosas reformas en los últimos 20 años, centradas fundamentalmente en aumentar las penas, ampliar los verbos rectores y ensanchar el listado de delitos fuente, además de analizar la Sentencia C-191 de 2016 de la Corte Constitucional, que declaró inexequible el aparte "o realice cualquier otro acto para ocultar o encubrir su origen ilícito", así como las opiniones disidentes al mencionado fallo.

El profesor Hernández concluye su texto al advertir que la profusa normativa expedida refleja el compromiso del país con la comunidad internacional para combatir este flagelo. Sin embargo, es necesario revisar ciertos temas relacionados con tal tarea: la situación de los delitos de omisión de control, la relación entre Reportes de Operaciones Sospechosas (ROs) a la Unidad de Información y Análisis Financiero (UIAF) y decisiones de las autoridades y la aparente inversión de la carga de la prueba que se puede presentar en los procesos judiciales por blanqueo de capitales.

El segundo capítulo de la obra, de la profesora Constanza Vargas Sanmiguel (2020), versa sobre los instrumentos internacionales sobre lavado de activos a los cuales el Estado colombiano se ha adscrito, así como las recomendaciones de organismos internacionales que también tratan esta problemática. Así, la autora empieza con la Convención de Viena de 1988, 
considerada el punto de partida de la lucha contra el delito en cuestión, en la que se aborda, como estrategia para combatir el tráfico de estupefacientes, la necesidad de atacar las ganancias de esta economía ilícita y cómo dicha tarea puede ser obstruida por las maniobras de lavado o blanqueo sobre tales riquezas, por esto surge la necesidad de tipificar, penalmente, dichos comportamientos. Posteriormente, se aborda la Declaración de Principios de Basilea de 1988, en la que se parte del reconocimiento del sector bancario como un sector vulnerable al reciclaje de dinero y con el cual se debe contar con el propósito de evitar que sea utilizado para tal fin, por esto es necesario realizar una gestión de conocimiento de clientes y cooperar activamente con las autoridades judiciales.

Luego se abordan las Cuarenta Recomendaciones del Grupo de Acción Financiero Internacional (GAFI), instrumento de vital importancia, en la medida que, luego de posteriores reformas, dio vía para que el lavado de activos se pudiera predicar de otros delitos diferentes al narcotráfico. Finalmente, la autora cita la Convención de Palermo de 2000, instrumento que sigue la tendencia de romper el vínculo exclusivo entre el lavado de activos y el narcotráfico, además de incluir como delito fuente cualquier conducta relacionada con la criminalidad organizada, y dejar al arbitrio de los Estados contratantes la decisión de castigar o no el autolavado de activos. Luego de abordar estos instrumentos, la profesora Vargas se dirige a otros, como el Reglamento Modelo del Control del Abuso de Drogas (CICAD) y lo emanado de la Alianza del Pacífico. La autora concluye que el Estado colombiano ha modificado su normativa interna para estar en sincronía con lo dispuesto por la comunidad internacional para combatir este delito, compromiso que no termina, ya que Colombia continúa sus esfuerzos conjuntos con otros países para responder a esta conducta nociva.

El tercer capítulo, de autoría de los profesores Adolfo Murillo y Mónica Caicedo (2020), aborda la dimensión trasnacional del lavado de activos. Los autores parten de reconocer a la globalización como el contexto para el surgimiento de la criminalidad trasnacional, para luego estudiar las características de los delitos trasnacionales, en particular su distinción con el concepto de delito internacional. Acto seguido, se plantea el lavado de activos como un delito de orden trasnacional, idea que trae algunas discusiones, tales como la competencia territorial para juzgar este delito, en virtud del lugar de su comisión, asunto que está lejos de ser considerado como pacífico. Ante este escenario, se traen a colación las medidas que se han adoptado para enfrentar la criminalidad trasnacional y, en particular, el blanqueo de capitales, en las que destacan la cooperación internacional y la expedición de instrumentos internacionales. Así, los autores plantean cómo este tipo de criminalidad no puede ser enfrentada con la versión clásica o tradicional del derecho penal y con esfuerzos aislados de cada país, sino que, ante un problema global, la solución también deber ser global, en la que se coordinen esfuerzos con el fin de combatir el lavado de activos, en particular, y la delincuencia trasnacional y organizada, en general. 
En el cuarto capítulo, los profesores Juan Pablo Rodríguez y René Castro (2020) ponen de presente la evaluación que se hizo de Colombia, por parte del Fondo Monetario Internacional (FMI), sobre el cumplimiento de las Cuarenta (40) Recomendaciones del GAFI. Dicha evaluación, señalan los autores, arrojó resultados para tener muy en cuenta, como que el país investiga y procesa el lavado de activos efectivamente, pero no acorde con sus riesgos de blanqueo de capitales o que la supervisión antilavado de activos y contra la financiación del terrorismo no está totalmente sincronizada con el enfoque basado en riesgos, existiendo brechas en la supervisión de actividades y profesiones no financieras designadas. En este contexto, los autores proponen acciones prioritarias, entre otras, como el mayor apoyo de la UIAF a las distintas autoridades para sus investigaciones sobre estos dos delitos, una retroalimentación (por parte de la UIAF) a los sujetos obligados sobre la calidad de los Reportes de Operaciones Sospechosas (ROs) y ampliar el alcance de las investigaciones para incluir los delitos fuente distintos al narcotráfico que son considerados de alto riesgo, según la Evaluación Nacional de Riesgo. Una vez establecidas unas consideraciones sobre el Reporte de Operaciones Sospechosas (ROS), los profesores Rodríguez y Castro proceden a realizar una propuesta para determinar un nuevo modelo de inteligencia financiera, específicamente uno de inteligencia financiera compartida, en el que resaltan el diálogo periódico entre las distintas entidades (públicas y privadas) y su armónica colaboración, tareas que desembocan, según muestra la experiencia de distintos países, en información de calidad que lleva a resultados concretos en contra de estos delitos.

El quinto capítulo, a cargo del profesor Yezid Viveros Castellanos (2020), versa sobre el delito de testaferrato, contenido en el artículo 326 de la Ley 599 de 2000. El autor inicia con una reseña histórica de este tipo, que empieza con el Decreto 1856 de 1989 (dictado al amparo del estadio de conmoción interior) y que luego continúa con el Código Penal de 2000, que incorpora este delito permanentemente al ordenamiento nacional. Luego, el profesor Viveros Castellanos procede a realizar un exhaustivo listado de características de este tipo penal (en el que resalta, entre otros, su elemento subjetivo especial, la posibilidad de concebir la modalidad tentada y su condición de delito permanente) y el análisis concreto de sus elementos estructurales, tales como los sujetos, la conducta y el bien jurídico tutelado (en el que resalta su carácter pluriofensivo). Acto seguido, el autor realiza una clasificación del testaferrato en función de la recepción o no de una remuneración por parte del sujeto activo de esta conducta, para luego informar los pronunciamientos jurisprudenciales que se han realizado sobre la consumación de este delito y su consideración como delito permanente, y sobre cómo la medida provisional del comiso no suspende la calidad de testaferro.

En el sexto capítulo, la profesora Tatiana Vargas Nieto (2020) expone cómo los criptoactivos pueden constituirse en un mecanismo para lavar activos, que dan lugar a una nueva tipología para que este ilícito se materialice. La autora parte de identificar una inquietud enormemente compleja: ¿Los criptoactivos pueden ser considerados como moneda? Una vez la autora trae a colación los distintos conceptos que existen en este campo (Bitcoin, Ether, Litecoin, Ripple), 
concluye que no constituyen moneda, sino bienes muebles intangibles y que si se realiza alguno de los verbos rectores que trae el artículo 323 del Código Penal colombiano, a través de estos bienes, se estaría en un evento de lavado de activos y la Fiscalía General de la Nación entraría a investigar para dar con los responsables. Sin embargo, dicha tarea, como lo plantea la profesora Vargas Nieto, no es para nada fácil, en la medida que quienes negocian con estos instrumentos no siguen los protocolos de prevención y detección del blanqueo de capitales, no están vigilados por entidad alguna y no deben hacer reportes a las autoridades de inteligencia financiera.

El séptimo y último capítulo de la obra, a cargo de los profesores Mónica Caicedo Lozada y Adolfo Murillo Granados (2020), se centra en la utilización de determinados contratos internacionales como mecanismos para el reciclaje de dinero, los cuales engrosan las tipologías que sirven para este fin. Los autores traen a colación los contratos de factoring, underwriting y el de joint venture, para dar a conocer que su escasa regulación, gran complejidad, aptitud para mover fuertes sumas de dinero y difícil detección (derivada del empleo de servicios altamente profesionales y especializados) los hacen idóneos para lavar activos.

La valía de la obra radica en que no solo se establecen las consideraciones dogmáticas y descriptivas sobre el lavado de activos y cuestiones afines, sino que presenta un estudio crítico hacia determinadas aristas sobre este complejo delito y exponen las situaciones favorables y novedosas para su materialización, labor que es encomiable en el sentido que aporta un insumo que puede permitir a las distintas autoridades que tienen como misión luchar contra este flagelo (el legislador que diseña las normas sancionatorias, el operador judicial encargado de impartirlas y la autoridad administrativa encargada de establecer y vigilar el cumplimiento de las normas de prevención y detección del lavado de activos) concebir nuevas estrategias para cumplir su tarea.

Sea esta la oportunidad para felicitar al equipo redactor de esta obra, a su coordinador académico, a la Universidad de Ibagué y al Grupo de Investigación Zoon Politikon (adscrito a esta prestigiosa casa de estudios) por la elaboración de este trabajo, que, junto con las obras Aspectos actuales del derecho penal económico en Colombia (Hernández, 2019) y Aspectos actuales de la responsabilidad penal de la persona jurídica en Colombia (Hernández, 2020c), también del mismo grupo de investigación, se constituye en un referente obligatorio para el estudio del derecho penal económico en Colombia.

\section{Referencias}

Caicedo Lozada, M., \& Murillo Granados, A. (2020). Algunos contratos mercantiles internacionales como instrumentos para el lavado de activos. En H.A. Hernández Quintero (Coord.), La eficacia de las normas de prevención, detección y sanción del lavado de activos en Colombia (pp. 135-150). Ibagué, Colombia: Ediciones Unibagué. Recuperado de https://doi.org/10.35707/978958754330807

Hernández Quintero, H. A. (Coord.). (2019). Aspectos actuales del derecho penal económico en Colombia. Ibagué, Colombia: Ediciones Unibagué. Recuperado de https://doi.org/10.35707/9789587543216 
Hernández Quintero, H.A. (Coord.). (2020a). La eficacia de las normas de prevención, detección y sanción del lavado de activos en Colombia. Ibagué, Colombia: Ediciones Unibagué. Recuperado de https://doi.org/10.35707/9789587543308

Hernández Quintero, H. A. (2020b). Evolución en la regulación administrativa y penal del lavado de activos en procura de la eficacia en su detección, prevención y sanción. En H.A. Hernández Quintero (Coord.), La eficacia de las normas de prevención, detección y sanción del lavado de activos en Colombia (pp. 11-38). Ibagué, Colombia: Ediciones Unibagué. Recuperado de https://doi. org/10.35707/9789587543330801

Hernández Quintero, H. A. (Coord.). (2020c). Aspectos actuales de la responsabilidad penal de la persona jurídica en Colombia. Ibagué, Colombia: Ediciones Unibagué. Recuperado de https://doi. org/10.35707/9789587543544

Murillo Granados, A., \& Caicedo Lozada, M. (2020). Eficacia de las medidas adoptadas para enfrentar el lavado de activos como delito transnacional. En H.A. Hernández Quintero (Coord.), La eficacia de las normas de prevención, detección y sanción del lavado de activos en Colombia (pp. 61-90). Ibagué, Colombia: Ediciones Unibagué. Recuperado de https://doi.org/10.35707/978958754330803

Rodríguez C., J. P., \& Castro Vaca, R. M. (2020). Evaluación del modelo de Colombia sobre el riesgo de lavado de activos y financiación del terrorismo. En H.A. Hernández Quintero (Coord.), La eficacia de las normas de prevención, detección y sanción del lavado de activos en Colombia (pp. 91-105). Ibagué, Colombia: Ediciones Unibagué. Recuperado de https://doi.org/10.35707/978958754330804

Sentencia C-191 (2016). Corte Constitucional de Colombia. Magistrado Ponente: Alejandro Linares Cantillo.

Vargas Nieto, T. (2020). Criptoactivos y las normas antilavado. En H.A. Hernández Quintero (Coord.), La eficacia de las normas de prevención, detección y sanción del lavado de activos en Colombia. (pp. 117-134). Ibagué, Colombia: Ediciones Unibagué. Recuperado de https://doi. org/10.35707/978958754330806

Vargas Sanmiguel, C. (2020). Compromisos internacionales del Estado colombiano en la lucha contra el lavado de activos. En H.A. Hernández Quintero (Coord.), La eficacia de las normas de prevención, detección y sanción del lavado de activos en Colombia (pp. 39-59). Ibagué, Colombia: Ediciones Unibagué. Recuperado de https://doi.org/10.35707/978958754330802

Viveros Castellanos, Y. (2020). Apuntes sobre el testaferrato. En H.A. Hernández Quintero (Coord.), La eficacia de las normas de prevención, detección y sanción del lavado de activos en Colombia (pp. 107-115). Ibagué, Colombia: Ediciones Unibagué. Recuperado de https://doi.org/10.35707/978958754330805 